\title{
Factors associated with the non-wear of mandibular dentures in the Brazilian public primary health care
}

\author{
Mara Rodrigues MARTINS(a) \\ Marco Túlio Moreira de SOUZA(a) \\ Juliene Fonte BOA ${ }^{(b)}$ \\ Débora Emrich MAGALHÃES(c) \\ Andreia Maria Duarte VARGAS(a) \\ Luís Otávio Miranda COTA(d) \\ Aline Araujo SAMPAIO(a) \\ Efigênia Ferreira e FERREIRA ${ }^{(a)}$
}

(a) Universidade Federal de Minas Gerais UFMG, Department of Social and Preventive Dentistry, Belo Horizonte, MG, Brazil.

(b) Centro Universitário Newton Paiva, Belo Horizonte, MG, Brasil.

(c) Private clinic, Belo Horizonte, MG, Brasil.

(d) Universidade Federal de Minas Gerais UFMG, Departament of Clinic, Pathology and Surgery, Belo Horizonte, MG, Brasil.

Declaration of Interest: The authors certify that they have no commercial or associative interest that represents a conflict of interest in connection with the manuscript.

\section{Corresponding Author:}

Aline Araujo Sampaio

E-mail: alinea.sampaio@hotmail.com

hitps://doi.org/10.1590/1807-3107bor-2018.vol32.0100

Submitted: October 31, 2017

Accepted for publication: July 24, 2018

Last revision: August 22, 2018
Abstract: This study investigated factors that affect the use of complete conventional mandibular dentures (CCMD) by patients of the Brazilian Public Health Service. For this, two hundred and thirty one subjects who received CCMD in the Primary Health Care of the Public Health Service in Belo Horizonte - Brazil were evaluated and divided in Group 1 - irregular/ non-wear; Group 2 - regular wear. Multivariate logistic regression analysis was used to create predictive models for CCMD non-wear and included socio-demographic and biological variables, technical quality of CCMD, and user satisfaction. The prevalence of CCMD non-wear was $41.10 \%$. The mean score of CCMD quality was 54.97 (0-100). Not wearing the CCMD was significantly associated with user satisfaction and technical quality $(p<0.05)$. The lack of retention of the CCMD was the most important factor in the evaluation of satisfaction and quality. The final predictive model (specificity $=92.65 \%$; $\mathrm{AROC}=0.8759$ ) for not wearing the CCMD retained the variables CCMD stability $(\mathrm{OR}=0.888 ; 95 \% \mathrm{CI}=0.827-0.954)$, freeway space $(\mathrm{OR}=0.916 ; 95 \% \mathrm{CI}=0.860-0.976)$, satisfaction with speech $(\mathrm{OR}=0.694 ; 95 \% \mathrm{CI}=0.612-0.786)$, and irregular $\mathrm{CCMD}$ edges $(\mathrm{OR}=3.185$; $95 \% \mathrm{CI}=1.478-6.864)$. Socio-demographic and biological variables were not associated with patients not wearing the CCMD, whereas technical quality and user satisfaction were strongly associated.

Keywords: Dentures; Health Services; Oral Health; Primary Health Care; Risk Factors.

\section{Introduction}

Edentulism is recognized as a serious public health problem ${ }^{1}$ and despite all the advances in dentistry, the need for complete conventional dentures has not decreased, mainly due to the increase of the elderly population. ${ }^{2}$ Complete tooth loss, a characteristic generally associated with low socioeconomic status, ${ }^{3}$ can affect oral and general health, as well as the quality of life of individuals.,

Treatment of edentulism with complete conventional dentures has been done for more than a century and, as a low $\operatorname{cost}^{6}$ and low complexity therapy, remains the standard treatment for this condition. However, a number of people do not wear their complete conventional mandibular dentures $(\mathrm{CCMD})^{7}$ and the decision is usually associated with the lack of retention and stability of their prosthesis. ${ }^{8,9}$ 
Several factors have been suggested as prognostic indicators for the therapy with complete conventional dentures: technical quality of the prosthesis, oral conditions, degree of residual ridge resorption, personality traits, edentulousness time, prior experience with dentures, sociodemographic factors, dentist-patient relationship, and patient expectations. ${ }^{10,11,12,13,14,15,16,17}$ These studies demonstrate a broad methodological variability that impairs comparisons of the results and reinforces the need for more research in this area. ${ }^{18}$ On the other hand, studies by Fenlon et al., ${ }^{17,19}$ using large samples and structural equation modelling, reported that the technical quality of the prosthesis and the conformation of the mandibular residual ridge are associated with the use of CCMD.

The study of factors associated with the clinical success of complete conventional dentures gained great importance with the advent of osseointegrated dental implants. The use of dental implants to provide stability and retention for CCMD and to overcome the functional difficulties of this therapy is well established. The McGill statement ${ }^{20}$ and York ${ }^{21}$ consensus concluded that two-implants retained removable complete dentures (overdentures) should be considered the treatment of choice and the minimum option to be offered to mandibular edentulous individuals. However, a single and universal treatment modality for mandibular edentulous individuals are still controversial due to the great variability of functional requirements of these patients, as well as to financial constraints., ${ }^{718}$

Currently in Brazil, according to the National Oral Health Policy, there are incentives for the counties to offer complete conventional dentures (since 2004) and dental implants (since 2010) for implant-retained and mucus-supported dentures in the public health service. However, the indication of this treatment modality for edentulous patients should be done with caution, since many factors are associated with the non-use of conventional total dentures that undoubtedly generate expenditures to the public health service with no significant oral and general health improvement of the population that uses the Brazilian public health service.

Based on this demographic, epidemiological, and political context, the present study aimed to investigate the association between sociodemographic, biological, and prosthetic factors with the non-wear of CCMD provided by the Primary Health Care of the public health service (Unified Health System, SUS - public health service sponsored by the government of Brazil) in Belo Horizonte, Minas Gerais, Brazil.

\section{Methods}

\section{Study design and sampling strategy}

A cross-sectional study was done with people wearing upper and lower complete conventional dentures for at least 1 year, provided by SUS Primary Health Care in Belo Horizonte, Brazil. This city is located in the Southeastern region of Brazil and has 2,375,151 inhabitants. ${ }^{22}$ The Primary Health Care network of Belo Horizonte consists of 144 Basic Health Units distributed in nine health districts.

The sample size of 231 individuals was determined using Epi Info 6.0 and the ratio estimation formula, assuming a $95 \%$ confidence interval, $\alpha$ error of $5 \%$, and a $15 \%$ prevalence of bimaxillary conventional complete denture requirement in the elderly population. ${ }^{23}$

Sample selection was performed through simple random sampling system. Initially, lists of the complete conventional dentures fabricated in Belo Horizonte from August 2010 to November 2011 were obtained. Of the 1075 individuals found, 373 received only maxillary, 99 received only mandibular, and 603 received upper and lower dentures. Of these 603 individuals, 31 were excluded because they were rehabilitated by the Secondary Health Care (CEO Centro de Especialidades Odontológicas), giving a final population of 572 , of which 231 were randomly selected for the study through EPI INFO 6.0. The selected individuals were attended in 43 Basic Health Units.

At first, the Basic Health Units scheduled the selected individuals for examination appointments. Those who failed to attend were searched for at their residences. Individuals who were not found in three attempts were excluded and a new individual was selected. The inclusion criterion was having bimaxillary complete conventional dentures done in the Primary Health Care in Belo Horizonte at least one year prior to the study (a period deemed necessary for patient compliance with the prostheses). 
Individuals were excluded, and a new one selected, if they presented physical or cognitive inabilities to answer the questionnaire, because of subjective questions. The information about inabilities was obtained from the Basic Health Unit records.

\section{Data collection}

Data collection was performed from November 2012 to January 2013 in the Basic Health Units or in the individuals' homes in a single moment, and consisted of an interview and clinical examination of the prosthesis and the oral cavity of the participants. Two previously trained researchers were responsible for data collection, comprising one interviewer (MTMS) and one examiner (MRM).

Participants answered a questionnaire with sociodemographic items (gender, age, family income, education level, marital status, number of individuals in the residence, number of children), and denturerelated items: whether or not the prostheses were being worn, number of prior prostheses, and edentulousness time. Satisfaction with prostheses was assessed through the methodology proposed by Sato et al. ${ }^{24}$ Clinical examination assessment of the technical quality of the prostheses was performed immediately after the interview using the methodology validated by Sato et $a .^{25}$

\section{Assessment of user satisfaction}

Denture satisfaction was assessed based on Sato et al. ${ }^{24}$ The methodology consisted of enquiring participants about the degree of satisfaction (very satisfied, satisfied, and dissatisfied) with seven factors: chewing, speech, pain, aesthetics, adaptation, retention, and comfort. The sum of the scores resulted in a final score for overall satisfaction varying from 0 to 100 . Individuals presenting scores $\geq 70$ were determined to be satisfied, while those presenting scores $<70$ were determined to be dissatisfied. Therefore, the overall satisfaction and the contribution of each factor were evaluated.

\section{Assessment of the technical quality of the prosthesis}

Technical quality was assessed in 3 steps: a. with the prostheses outside the oral cavity; $b$. the oral cavity without the prostheses; and c. with the prostheses placed in the oral cavity. First, dentures were examined for irregular or sharp edges and fractures. Then, with the prostheses in the mouth, the technical quality of was assessed according to the methodology proposed by Sato et al. ${ }^{25}$ The authors suggest a technical guideline to evaluate the following 7 clinical factors: arrangement of anterior teeth, interocclusal distance, stability of the mandibular prosthesis, occlusion, articulation, retention of the maxillary prosthesis, and extent of mandibular prosthesis. These factors are considered fundamental in the evaluation of the technical quality. Examination were performed under natural light and infection control strategies, with a wooden spatula, a horseshoe-shaped carbon film, a Willis ${ }^{\circledR}$ compass, and a Fox ${ }^{\circledR}$ ruler.

\section{Assessment of the quality of the mandibular alveolar ridge}

The position of the geni process and the mylohyoid line with respect to the crest of the alveolar ridge were evaluated, specifying whether they were above, at the level of, or below the crest using the method of Cawood and Howell. ${ }^{26}$ The height of the alveolar ridge on the symphysis region was measured using a Willis ${ }^{\circledR}$ compass. The presence of mucosal injuries as well as angular cheilitis were verified.

\section{Examiner calibration and agreement}

A theoretical training on the technical guidelines proposed by Sato et al. ${ }^{25}$ for the technical evaluation of the prostheses was conducted in three 8-hour duration meetings throughout October 2012. Afterwards, a pilot study with 20 individuals was conducted to verify the reproducibility of oral examinations (intra-examiner calibration), as well as a training process for the questionnaire application. The 20 individuals were examined again after 7 days. These data were excluded from the final sample. The Kappa test was used to assess examiner agreement, with values of 0.81 for quality of the prostheses and 0.97 for residual ridge evaluation. Then, a new meeting was held and all the necessary adjustments in data collection were discussed and implemented. No changes or adaptations in the methodology of the clinical examination of the prostheses were determined to be necessary. 


\section{Ethical considerations}

The present study was approved by the Ethics Research Committee of the Federal University of Minas Gerais (\#CAAE 06781912.8.0000.5149) and the City Hall of Belo Horizonte, complying with the 466/2012 resolution from the National Health Council. All participants provided an informed written consent.

\section{Statistical analysis}

Descriptive analyses were performed to characterize the sample. The dependent variable was determined to be "non-wear of CCMD", while the independent variables were: sociodemographic (gender, age, family income, education level, marital status, number of individuals in the residence, and number of children), individual-related (edentulousness time, previous experience with CCMD, anatomy of the residual alveolar ridge, and user satisfaction), and prosthesis-related (fractures, irregular borders, and technical quality). The sample was divided into 2 groups according to the dependent variable as follows: Group 1 - irregular wear/non-wear; Group 2 - regular wear. Normality of continuous variables was verified by the Kolmogorov-Smirnov test. Groups were compared regarding variables of interest through the Chi-square, the Mann-Whitney, and the independent $t$-tests, as appropriate. Logistic regression analyses were used to create predictive multivariate models for CCMD non-wear. Different models were thus created, according to the type of variables that were included: a. Sociodemographic model (gender, age, family income, education level, marital status, number of individuals in the residence, and number of children); $b$. User satisfaction model (chewing, speech, pain, aesthetics, adaptation of maxillary complete denture, CCMD retention, and comfort of maxillary complete denture); c. Technical quality of CCMD in the mouth (arrangement of anterior teeth, freeway space, CCMD stability, static occlusion (articulation), dynamic occlusion (laterality movements), CCMD retention, CCMD extension); d. Technical quality of CCMD outside the mouth (fractures, irregular borders); e.Complete final model (all variables retained in each of the previous cited models). In each model, all respective variables were entered and manually removed until only significant variables were retained ( $p \leq 0.05)$. Non-significant variables were kept in the model if they importantly interfered on the coefficients of the other variables. Post-hoc tests for all models were performed and sensitivity, specificity, and accuracy (area under the ROC curve - AROC) were determined.

All analyses were performed using SPSS software version 20.0 (Statistical Package for Social Sciences for Windows - SPSS Inc., Chicago, USA) after double entry. Results were determined to be significant if $p<0.05$ (significance level of 5\%).

\section{Results}

Sociodemographic characteristics of the sample are presented in Table 1. Age of the participants varied from 36 to 93 years (mean $66.68 \pm 10.98$ ). The sample predominantly consisted of females (62.3\%), with a low educational level $(93.9 \%$ of individuals with up to 8 years of schooling), an average family income of up to 3 minimum wages (97.4\%), and with a partner $(50.2 \%)$. No association was found between sociodemographic variables and the non-use of CCMD.

A large percentage of participants had a previous experience with CCMD (73.2\%), with a mean time of mandibular edentulism of $21.20 \pm 15.34$ years.

The evaluation of the mandibular borders showed that the geni process was located below the alveolar crest in $60.2 \%$, at the crest level in $22.1 \%$, and above the crest in $17.7 \%$ of the cases. The position of the mylohyoid line showed that in $51.1 \%$ of the cases it was below the alveolar crest, $33.8 \%$ at the level, and $15.2 \%$ above the alveolar crest. More than $15 \%$ of the evaluated jaws presented a VI degree ridge reabsorption. The mean height of the mandibular ridge in the symphysis region was $27.97 \pm 5.67 \mathrm{~mm}$. Time of edentulism, previous experience with CCD, and residual border anatomy were not associated with the non-use of CCMD, while irregular borders had a significant association $(p<0.001)$ (Table 2$)$.

In the evaluation of patients' satisfaction, $73.10 \%$ of the participants declared themselves satisfied with the CCMD. Overall satisfaction, as well as all 7 factors evaluated in the methodology, had a significant association $(p<0.05)$ with the non-use of CCMD. In 
Table 1. Association between the non-wear of complete conventional mandibular denture (CCMD) and sociodemographic variables.

\begin{tabular}{|c|c|c|c|c|}
\hline \multirow{2}{*}{ Variables } & Total sample & Irregular/non-wear of CCMD & Regular wear of CCMD & \multirow{2}{*}{$p$-value* } \\
\hline & $(n=231)$ & $(n=95)$ & $(n=136)$ & \\
\hline \multicolumn{5}{|l|}{ Gender } \\
\hline Male & 87 (37.7\%) & $36(37.9 \%)$ & $51(37.5 \%)$ & \multirow[t]{2}{*}{$0.951^{* *}$} \\
\hline Female & $144(62.3 \%)$ & $59(62.1 \%)$ & 85 (62.5\%) & \\
\hline \multicolumn{5}{|l|}{ Age } \\
\hline Up to 60 years & $67(29.0 \%)$ & $25(26.3 \%)$ & $42(30.9 \%)$ & \multirow{4}{*}{$0.830^{* *}$} \\
\hline 61 to 70 years & 79 (34.2\%) & $32(33.7 \%)$ & $47(34.6 \%)$ & \\
\hline 71 to 80 years & $61(26.4 \%)$ & 27.(28.4\%) & $34(25 \%)$ & \\
\hline 81 years or more & $24(10.4 \%)$ & $11(11.6 \%)$ & $13(9.6 \%)$ & \\
\hline \multicolumn{5}{|l|}{ Years of schooling } \\
\hline Up to 8 years & 217 (93.9\%) & $91(95.8 \%)$ & $126(92.6 \%)$ & \multirow[t]{2}{*}{$0.325^{* *}$} \\
\hline 8 years or more & $14(6.6 \%)$ & $4(4.2 \%)$ & $10(7.4 \%)$ & \\
\hline \multicolumn{5}{|l|}{ Family income } \\
\hline Without income & 48 (20.8\%) & $20(21.1 \%)$ & $28(20.6 \%)$ & \multirow{4}{*}{$0.555^{* *}$} \\
\hline Less than one minimum wage & 32 (13.9\%) & $16(16.8 \%)$ & $16(11.8 \%)$ & \\
\hline 1 to 3 minimum wages & $146(63.2 \%)$ & $58(61.1 \%)$ & $88(64.7 \%)$ & \\
\hline More than 3 minimum wages & $5(2.2 \%)$ & $1(1.1 \%)$ & $4(2.9 \%)$ & \\
\hline \multicolumn{5}{|l|}{ Marital status } \\
\hline With companion & $116(50.2 \%)$ & 55 (57.9\%) & $61(44.9 \%)$ & \multirow[t]{2}{*}{$0.269^{* *}$} \\
\hline Without companion & $115(49.8 \%)$ & $40(42.1 \%)$ & $75(48.2 \%)$ & \\
\hline Number of individuals in the residence & $\begin{array}{c}3.36 \pm 2.07 \\
(0-13)\end{array}$ & $\begin{array}{c}3.60 \pm 2.34 \\
(1-12)\end{array}$ & $\begin{array}{c}3.19 \pm 1.84 \\
(0-13)\end{array}$ & $0.338^{* * *}$ \\
\hline Number of children & $\begin{array}{c}4.26 \pm 3.25 \\
(0-19)\end{array}$ & $\begin{array}{c}4.48 \pm 3.47 \\
(0-19)\end{array}$ & $\begin{array}{c}4.11 \pm 3.08 \\
(0-17)\end{array}$ & $0.422^{* * *}$ \\
\hline
\end{tabular}

${ }^{*}$ comparisons between irregular/non-wear of CCMD and regular wear of CCMD; ${ }^{* *}$ Chi-square test; §independent t-test; ${ }^{* * *}$ Mann-Whitney test.

Table 2. Association between the non-wear of complete conventional mandibular denture (CCMD) and individual factors.

\begin{tabular}{|c|c|c|c|c|}
\hline \multirow{2}{*}{ Variables } & Total sample & Irregular/non-wear of CCMD & Regular wear of CCMD & \multirow{2}{*}{$p$-value } \\
\hline & $(n=231)$ & $(n=95)$ & $(n=136)$ & \\
\hline \multicolumn{5}{|l|}{ Fracture in mandibular base } \\
\hline Yes & 11 (4.8\%) & $5(5.3 \%)$ & $6(4.4 \%)$ & \multirow[t]{2}{*}{$0.765^{*}$} \\
\hline No & $220(95.2 \%)$ & $90(94.7 \%)$ & $130(95.6 \%)$ & \\
\hline \multicolumn{5}{|l|}{ Irregular borders } \\
\hline Yes & $64(27.7 \%)$ & $42(44.2 \%)$ & $22(16.2 \%)$ & \multirow[t]{2}{*}{$<0.001^{*}$} \\
\hline No & $167(72.3 \%)$ & $53(55.8 \%)$ & 114 (83.8\%) & \\
\hline $\begin{array}{l}\text { Height of the alveolar ridge on the } \\
\text { symphysis region }(\mathrm{mm})\end{array}$ & $\begin{array}{c}27.97 \pm 5.67 \\
(10-45)\end{array}$ & $\begin{array}{c}28.14 \pm 5.9 \\
(11-40)\end{array}$ & $\begin{array}{l}27.86 \pm 5.51 \\
(10-45)\end{array}$ & $0.364^{* *}$ \\
\hline \multicolumn{5}{|l|}{ Position of the geni process } \\
\hline Above the alveolar crest & $41(17.7 \%)$ & $16(16.8 \%)$ & $25(18.4 \%)$ & \multirow{3}{*}{$0.730^{*}$} \\
\hline At the alveolar crest level & $51(22.1 \%)$ & 19 (20\%) & $32(23.5 \%)$ & \\
\hline Below the alveolar crest & $139(60.2 \%)$ & $60(63.2 \%)$ & $79(58.1 \%)$ & \\
\hline \multicolumn{5}{|l|}{ Position of the mylohyoid line } \\
\hline Above the alveolar crest & $35(15.2 \%)$ & $15(15.8 \%)$ & $20(14.7 \%)$ & \multirow{3}{*}{$0.684^{*}$} \\
\hline At the alveolar crest level & 78 (33.8\%) & 29 (30.5\%) & 49 (36\%) & \\
\hline Below the alveolar crest & $118(51.1 \%)$ & $51(53.7 \%)$ & $67(49.3 \%)$ & \\
\hline \multicolumn{5}{|l|}{ Number of lower dentures } \\
\hline 1 & $96(41.6 \%)$ & $44(46.6 \%)$ & $46(33.8 \%)$ & \multirow{4}{*}{$0.235^{*}$} \\
\hline 2 & 57 (24.7\%) & $18(18.9 \%$ & $37(27.2 \%)$ & \\
\hline 3 or more & 25 (10.8\%) & 10 (10.5\%) & $14(10.3 \%)$ & \\
\hline not applicable & 53 (22.9\%) & 23 (24.2\%) & 39 (28.7\%) & \\
\hline Time since lower tooth loss (years) & $\begin{array}{c}21.20 \pm 15.34 \\
(1-50)\end{array}$ & $\begin{array}{c}21.78 \pm 14.08 \\
(1-50)\end{array}$ & $\begin{array}{c}20.80 \pm 16.20 \\
(1-50)\end{array}$ & $0.521^{* *}$ \\
\hline Time of CCMD usage (years) & $\begin{array}{c}18.65 \pm 15.57 \\
(1-50)\end{array}$ & $\begin{array}{c}18.41 \pm 14.57 \\
(1-50)\end{array}$ & $\begin{array}{c}18.82 \pm 16.28 \\
(1-50)\end{array}$ & $0.865^{* *}$ \\
\hline
\end{tabular}

*Chi-square test; ${ }^{* *}$ Mann-Whitney test. 
group 1, all factors presented a lower satisfaction score and higher percentage of dissatisfaction when compared to group 2. Retention of the lower prosthesis had the highest percentage of dissatisfied people in groups 1 and 2. The best performance (lower percentage of dissatisfied) in both groups was for the aesthetics factor. Table 3 shows the association between satisfaction and the non-use of the CCMD.

In the total sample, the percentage of people using and not using their CCMD was 58.9\% and $41.1 \%$, respectively. The overall quality score of the prostheses was 54.97. In group 1 (not using the CCMD), the overall CCD quality score was 42.96 and in group 2 (using the CCMD), the score was 65.46. The results of the quality evaluation for each clinical criterion and association between the technical quality and the non-use of the CCMD are presented in Table 4.

In group 1, the factors with the worst evaluation (greater percentage of prostheses evaluated worst) were: retention of the CCMD (69.5\% moved easily), dynamic occlusion $(48.4 \%$ of CCD had one nonworking side only) and stability of the CCMD (43.2\% swung). Aesthetics was the factor with the best evaluation (Table 4).

Table 3. Association between the non-wear of complete conventional mandibular denture (CCMD) and user satisfaction.

\begin{tabular}{|c|c|c|c|c|}
\hline \multirow{2}{*}{ Variables } & Total sample & Irregular/non-wear of CCMD & Regular wear of CCMD & \multirow{2}{*}{ p-value* } \\
\hline & $(n=231)$ & $(n=95)$ & $(n=136)$ & \\
\hline $\begin{array}{l}\text { General satisfaction with the } \\
\text { prostheses }\end{array}$ & $\begin{array}{c}73.18 \pm 34.45 \\
(0-100)\end{array}$ & $\begin{array}{c}48.14 \pm 37.10 \\
(0-100)\end{array}$ & $\begin{array}{c}90.66 \pm 17.71 \\
(11-100)\end{array}$ & $<0.001^{* * *}$ \\
\hline Satisfaction with chewing & $\begin{array}{c}8.84 \pm 5.93 \\
(0-14)\end{array}$ & $\begin{array}{c}4.51 \pm 5.42 \\
(0-14)\end{array}$ & $\begin{array}{c}11.87 \pm 4.11 \\
(0-14)\end{array}$ & $<0.001^{* * *}$ \\
\hline Very satisfied & $124(53.7 \%)$ & 19 (20\%) & $105(77.2 \%)$ & \multirow{3}{*}{$<0.001^{* *}$} \\
\hline Satisfied & $51(22.1 \%)$ & 27 (28.4\%) & $24(17.6 \%)$ & \\
\hline Not satisfied & $56(24.2 \%)$ & $49(51.6 \%)$ & $7(5.1 \%)$ & \\
\hline Satisfaction with speech & $\begin{array}{c}6.66 \pm 3.52 \\
(0-9)\end{array}$ & $\begin{array}{c}4.26 \pm 3.82 \\
(0-9)\end{array}$ & $\begin{array}{c}8.34 \pm 1.99 \\
(0-9)\end{array}$ & $<0.001^{* * *}$ \\
\hline Very satisfied & $143(61.9 \%)$ & $25(26.3 \%)$ & $118(86.8 \%)$ & \multirow{3}{*}{$<0.001^{* *}$} \\
\hline Satisfied & 42 (18.2\%) & $30(31.6 \%)$ & $12(8.8 \%)$ & \\
\hline Not satisfied & $46(19.9 \%)$ & $40(42.1 \%)$ & $6(4.4 \%)$ & \\
\hline Satisfaction with aesthetics & $\begin{array}{c}10.76 \pm 4.61 \\
(0-13)\end{array}$ & $\begin{array}{c}8.54 \pm 5.87 \\
(0-13)\end{array}$ & $\begin{array}{c}12.32 \pm 2.49 \\
(0-13)\end{array}$ & $<0.001^{* * *}$ \\
\hline Very satisfied & 165 (71.4\%) & $48(50.5 \%)$ & $117(86 \%)$ & \multirow{3}{*}{$<0.001^{* *}$} \\
\hline Satisfied & 31 (13.4\%) & $17(17.9 \%)$ & $14(10.3)$ & \\
\hline Not satisfied & 35 (15.2\%) & $30(31.6 \%)$ & $5(3.7 \%)$ & \\
\hline $\begin{array}{l}\text { Satisfaction with adaptation of the } \\
\text { maxillary complete denture }\end{array}$ & $\begin{array}{c}13.39 \pm 7.12 \\
(0-18)\end{array}$ & $\begin{array}{c}9.09 \pm 8.31 \\
(0-18)\end{array}$ & $\begin{array}{c}16.40 \pm 3.98 \\
(0-18)\end{array}$ & $<0.001^{* * *}$ \\
\hline Very satisfied & $143(61.9 \%)$ & $35(36.8 \%)$ & 108 (79.4\%) & \multirow{3}{*}{$<0.001^{* *}$} \\
\hline Satisfied & $40(17.3 \%)$ & 18 (18.9\%) & $22(16.2 \%)$ & \\
\hline Not satisfied & $48(20.8 \%)$ & $42(44.2 \%)$ & $6(4.4 \%)$ & \\
\hline Satisfaction with CCMD retention & $\begin{array}{c}9.10 \pm 6.58 \\
(0-15)\end{array}$ & $\begin{array}{c}4.24 \pm 5.94 \\
(0-15)\end{array}$ & $\begin{array}{c}12.49 \pm 4.56 \\
(0-15)\end{array}$ & $<0.001^{* * *}$ \\
\hline Very satisfied & 99 (42.9\%) & $10(10.5 \%)$ & 89 (65.4\%) & \multirow{3}{*}{$<0.001^{* *}$} \\
\hline Satisfied & $56(24.2 \%)$ & $23(24.2 \%)$ & $33(24.3 \%)$ & \\
\hline Not satisfied & $76(32.9 \%)$ & $62(65.3 \%)$ & $14(10.3 \%)$ & \\
\hline $\begin{array}{l}\text { Satisfaction with the comfort of } \\
\text { maxillary complete denture }\end{array}$ & $\begin{array}{c}14.60 \pm 7.57 \\
(0-19)\end{array}$ & $\begin{array}{c}10.09 \pm .9 .09 \\
(0-19)\end{array}$ & $\begin{array}{c}17.74 \pm 3.96 \\
(0-19)\end{array}$ & $<0.001^{* * *}$ \\
\hline Very satisfied & $148(64.1 \%)$ & 37 (38.9\%) & $111(81.6 \%)$ & \multirow{3}{*}{$<0.001^{* *}$} \\
\hline Satisfied & $35(15.2 \%)$ & $16(16.8 \%)$ & 19 (14\%) & \\
\hline Not satisfied & $48(20.8 \%)$ & $42(44.2 \%)$ & $6(4.4 \%)$ & \\
\hline Satisfaction with pain & $\begin{array}{c}9.83 \pm 4.25 \\
(0-12)\end{array}$ & $\begin{array}{c}7.41 \pm 5.44 \\
(0-12)\end{array}$ & $\begin{array}{c}11.52 \pm 1.78 \\
(0-12)\end{array}$ & $<0.001^{* *}$ \\
\hline Very satisfied & $126(54.5 \%)$ & $33(34.7 \%)$ & $104(76.5 \%)$ & \multirow{3}{*}{$<0.001^{* *}$} \\
\hline Satisfied & 69 (29.9\%) & $40(42.1 \%)$ & $29(21.3 \%)$ & \\
\hline Not satisfied & $36(15.6 \%)$ & $22(23.2 \%)$ & $3(2.2 \%)$ & \\
\hline
\end{tabular}

${ }^{*}$ Comparisons between irregular/non-wear and regular wear of CCMD; ${ }^{* *}$ Chi-square test; ${ }^{* * *}$ Mann-Whitney test. 
In group 2, CCMD retention also had the worst performance; $52.2 \%$ of the prostheses moved easily. The arrangement of anterior teeth (74.3\%), together with static occlusion (58.8\%), stability of the CCMD (58.8\%), and freeway space $(57.4 \%)$ were the criteria with the best evaluation. All criteria related to the technical quality of the prostheses presented a statistically significant difference $(p<0.05)$ between groups wearing and not wearing the CCMD (Table 4).

Table 5 presents the multivariate logistic regression models for the non-use of the CCMD. Model 1 (sociodemographic) maintained the marital status $(\mathrm{OR}=0.556$; 95\% CI=0.324-0.955, $\mathrm{p}<0.034)$; model 2 (user satisfaction) maintained satisfaction with speech $(\mathrm{OR}=0.79 ; 95 \% \mathrm{CI}=0.683-0.916, \mathrm{p}<0.002)$ and satisfaction with CCMD retention ( $\mathrm{OR}=0.858$; $95 \% \mathrm{CI}=0.803-0.916, \mathrm{p}<0.001$ ); model 3 (quality of the CCMD in the mouth) maintained speaking space $(\mathrm{OR}=0.895 ; 95 \% \mathrm{CI}=0.848-0.946, \mathrm{p}<0.001)$, stability of mandibular prosthesis $(\mathrm{OR}=0.893 ; 95 \% \mathrm{CI}=0.835-0.955$, $\mathrm{p}=0.001)$ and extension of the mandibular prosthesis $(\mathrm{OR}=0.893 ; 95 \% \mathrm{CI}=0.836-0.954, \mathrm{p}=0.001)$; and model

Table 4. Association between the non-wear of complete conventional mandibular denture (CCMD) and the technical quality of the prostheses.

\begin{tabular}{|c|c|c|c|c|}
\hline \multirow{2}{*}{ Variables } & Total sample & Irregular/non-wear of CCMD & Regular wear of CCMD & \multirow{2}{*}{ p-value* } \\
\hline & $(n=231)$ & $(n=95)$ & $(n=136)$ & \\
\hline General quality of the prostheses & $\begin{array}{c}54.97 \pm 23.60 \\
(0-100)\end{array}$ & $\begin{array}{c}42.96 \pm 20.81 \\
(0-89)\end{array}$ & $\begin{array}{c}65.46 \pm 19.86 \\
(0-100)\end{array}$ & $<0.001^{* * *}$ \\
\hline Anterior teeth arrangement & $\begin{array}{c}9.40 \pm 5.27 \\
(0-13)\end{array}$ & $\begin{array}{c}8.32 \pm 5.66 \\
(0-13)\end{array}$ & $\begin{array}{c}\text { 10. } 15 \pm 4.85 \\
(0-13)\end{array}$ & $<0.006^{* * *}$ \\
\hline None of the factors is harmonious & 9 (3.9\%) & $8(8.4 \%)$ & $1(0.7 \%)$ & \multirow{3}{*}{$0.003^{* *}$} \\
\hline Only one of the two factors is harmonious & $65(28.1 \%)$ & $31(32.6 \%)$ & $34(25.0 \%)$ & \\
\hline Height and inclination of teeth harmonize & $157(68.0 \%)$ & $56(58.9)$ & $101(74.3 \%)$ & \\
\hline Freeway space & $\begin{array}{c}5.73 \pm 5.70 \\
(0-12)\end{array}$ & $\begin{array}{c}3.65 \pm 5.16 \\
(0-12)\end{array}$ & $\begin{array}{c}7.18 \pm 5.62 \\
(0-12)\end{array}$ & $0.001^{* * *}$ \\
\hline$<1 \mathrm{~mm}$ or $>7 \mathrm{~mm}$ & $52(22.5 \%)$ & $34(35.8 \%)$ & $18(13.2 \%)$ & \multirow{3}{*}{$0.001^{* *}$} \\
\hline$>3 \mathrm{~mm}$ to $7 \mathrm{~mm}$ & 75 (32.5\%) & $35(36.8 \%)$ & $40(29.4 \%)$ & \\
\hline $1 \mathrm{~mm}$ to $3 \mathrm{~mm}$ & $104(45.0 \%)$ & $26(27.4 \%)$ & $78(57.4 \%)$ & \\
\hline Stability of CCMD & $\begin{array}{c}7.79 \pm 4.87 \\
(0-12)\end{array}$ & $\begin{array}{c}5.64 \pm 5.16 \\
(0-12)\end{array}$ & $\begin{array}{c}9.29 \pm 4.04 \\
(0-12)\end{array}$ & $<0.001^{* * *}$ \\
\hline Instability (weighbridge) & $59(25.5 \%)$ & $41(43.2 \%)$ & $18(13.2 \%)$ & \multirow{3}{*}{$<0.001^{* *}$} \\
\hline Displacement beyond the normal standard & $66(28.6 \%)$ & $28(29.5 \%)$ & 38 (27.9\%) & \\
\hline Displacement within the normal standard & $106(45.9 \%)$ & $26(27.4 \%)$ & 80 (58.8\%) & \\
\hline Static occlusion & $\begin{array}{c}10.03 \pm 6.04 \\
(0-14)\end{array}$ & $\begin{array}{c}8.63 \pm 6.49 \\
(0-14)\end{array}$ & $\begin{array}{c}11.01 \pm 5.51 \\
(0-14)\end{array}$ & $<0.001^{* * *}$ \\
\hline Incorrect in both sides & $61(26.4 \%)$ & $34(35.8 \%)$ & 27 (19.9\%) & \multirow{3}{*}{$<0.001^{* *}$} \\
\hline Incorrect in one of the sides & $63(27.3 \%)$ & $34(35.8 \%)$ & $29(21.3 \%)$ & \\
\hline Correct in both sides & 107 (46.3\%) & $27(28.4 \%)$ & $80(58.8 \%)$ & \\
\hline Dynamic occlusion (articulation) & $\begin{array}{c}6.89 \pm 6.10 \\
(0-16)\end{array}$ & $\begin{array}{c}5.47 \pm 5.98 \\
(0-16)\end{array}$ & $\begin{array}{c}7.88 \pm 6.01 \\
(0-16)\end{array}$ & $0.003^{* * *}$ \\
\hline Contact on the side of non-working & $85(36.8 \%)$ & $46(48.4 \%)$ & $39(28.7 \%)$ & \multirow{3}{*}{$0.008^{* *}$} \\
\hline Contact on the working side & $93(40.3 \%)$ & $33(34.7 \%)$ & $60(44.1 \%)$ & \\
\hline Contact the working and non-working side & $53(22.9 \%)$ & $16(16.8 \%)$ & $37(27.2 \%)$ & \\
\hline CCMD retention & $\begin{array}{c}5.41 \pm 6.67 \\
(0-15)\end{array}$ & $\begin{array}{c}4.03 \pm 6.21 \\
(0-15)\end{array}$ & $\begin{array}{c}6.37 \pm 6.82 \\
(0-15)\end{array}$ & 0.009 \\
\hline Moves easily & 137 (59.3\%) & $66(69.5 \%)$ & $71(52.2 \%)$ & \multirow{3}{*}{$0.030^{* *}$} \\
\hline Moves with difficulty & $40(17.3 \%)$ & $13(13.7 \%)$ & 27 (19.9\%) & \\
\hline Does not shift & $54(23.4 \%)$ & $16(16.8 \%)$ & $38(27.9 \%)$ & \\
\hline CCMD extension & $\begin{array}{c}9.71 \pm 5.64 \\
(0-18)\end{array}$ & $\begin{array}{c}7.18 \pm 4.81 \\
(0-18)\end{array}$ & $\begin{array}{c}11.49 \pm 5.50 \\
(0-18)\end{array}$ & $<0.001^{* * *}$ \\
\hline No satisfactory point & $28(12.1 \%)$ & $21(22.1 \%)$ & $7(5.1 \%)$ & \multirow{3}{*}{$<0.001^{* *}$} \\
\hline 1 to 5 suitable points & $141(61.0 \%)$ & 65 (68.4\%) & $76(55.9 \%)$ & \\
\hline All points are satisfactory & $62(26.8 \%)$ & $9(9.5 \%)$ & $53(39 \%)$ & \\
\hline
\end{tabular}

${ }^{*}$ Comparisons between irregular/non-wear and regular wear of CCMD; ${ }^{* *}$ Chi-square test; ${ }^{* * *}$ Mann-Whitney test. 
Table 5. Predictive multivariate logistic models for the non-wear of complete conventional mandibular denture (CCMD).

\begin{tabular}{|c|c|c|c|}
\hline Multivariate models & Coefficient & $\mathrm{OR}(95 \% \mathrm{Cl})$ & $\mathrm{p}$-value \\
\hline \multicolumn{4}{|l|}{ Model 1 (Sociodemographic) } \\
\hline Marital status (without life partner) & -0.586 & $0.556(0.324-0.955)$ & 0.034 \\
\hline Age & 0.181 & $1.199(0.907-1.584)$ & 0.203 \\
\hline Constant & -0.290 & NA & 0.222 \\
\hline \multicolumn{4}{|l|}{ Model 2 (User satisfaction) } \\
\hline Speech & -0.234 & $0.791(0.683-0.916)$ & 0.002 \\
\hline CCMD retention & -0.153 & $0.858(0.803-0.916)$ & $<0.001$ \\
\hline Constant & 2.602 & NA & $<0.001$ \\
\hline \multicolumn{4}{|c|}{ Model 3 (Technical quality of CCMD inside the oral cavity) } \\
\hline Freeway space & -0.110 & $0.895(0.848-0.946)$ & $<0.001$ \\
\hline CCMD stability & -0.113 & $0.893(0.835-0.955)$ & 0.001 \\
\hline CCMD extension & -0.113 & $0.893(0.836-0.954)$ & 0.001 \\
\hline Constant & 2.134 & NA & $<0.001$ \\
\hline \multicolumn{4}{|c|}{ Model 4 (Technical quality of CCMD outside the oral cavity) } \\
\hline Irregular borders & 1.413 & $4.106(2.231-7.558)$ & $<0.001$ \\
\hline Constant & -0.766 & NA & $<0.001$ \\
\hline \multicolumn{4}{|l|}{ Model 5 (Complete final) } \\
\hline CCMD stability & -0.119 & $0.888(0.827-0.954)$ & 0.001 \\
\hline Speech & -0.366 & $0.694(0.612-0.786)$ & $<0.001$ \\
\hline Freeway space & -0.088 & $0.916(0.860-0.976)$ & 0.006 \\
\hline Irregular borders & 1.158 & $3.185(1.478-6.864)$ & 0.003 \\
\hline Constant & 3.165 & NA & $<0.001$ \\
\hline
\end{tabular}

4 (off-the-mouth CCMD quality) maintained irregular borders $(\mathrm{OR}=4,106 ; 95 \% \mathrm{CI}=2.231-7.558, \mathrm{p}<0.001)$. The final model maintained CCMD stability (OR =0.888; $95 \% \mathrm{CI}=0.827-0.954, \mathrm{p}=0.001)$, speech satisfaction $(\mathrm{OR}=0.694,95 \% \mathrm{CI}=0.612-0.786, \mathrm{p}<0.001)$, freeway space $(\mathrm{OR}=0.916,95 \% \mathrm{CI}=0.860-0.976, \mathrm{p}=0.006)$, and irregular borders $(\mathrm{OR}=3,185 ; 95 \% \mathrm{CI}=1.478-6.864$, $\mathrm{p}<0.001)$. It is important to note that the user satisfaction model presented the highest sensitivity value $(81.05 \%)$ while the final model had the highest specificity value (92.65\%); however, both presented similar accuracy values $(\mathrm{AROC}=0.8639$ and $\mathrm{AROC}$ $=0.8759$, respectively) .

\section{Discussion}

Results from the present study demonstrated that the percentage of people not regularly wearing the CCMD was high (41.1\%) among those who had received a CCMD (n=95), although a high number of individuals were satisfied with the prostheses received in the Brazilian Public Primary Health Care
(73.10\%). User satisfaction and technical quality were strongly associated with wear of the CCMD. The mean overall score for the quality of the prostheses was 54.97 (0-100), which can be considered a median score, and together with the prevalence of people not wearing the prostheses, highlights the need to improve the efficiency of the service.

The association between non-use of the CCMD with technical quality, which was demonstrated in the present study, is in accordance with previous studies. ${ }^{15,17,27}$. However, this association was not observed in other surveys. ${ }^{10,11,14}$

The presence of irregular borders in $44.2 \%$ of the CCMD observed in group 1 (irregular wear/not wearing the CCMD) emphasizes the importance of polishing and finishing procedures before prosthesis installation. Dental laboratories and dentists should be aware of the importance of these procedures, and Basic Health Units should provide strategies for these procedures to be properly done. The regression analysis confirmed that the presence of irregular borders is an important variable associated with the 
non-wear of the CCMD, increasing in about 3 times the chance of the patient not wearing the prosthesis.

This study showed that more than $50 \%$ of the prostheses presented no retention, that is, mandibular dentures moved easily in both groups. Moreover, the evaluation of CCMD stability showed that $43.2 \%$ of the prostheses were unstable in group 1 , while $13.2 \%$ were unstable in group 2 . These results suggested that the stability rather than the retention was the most important variable for the regular use of CCMD. This finding is supported by the study of Fenlon et al. ${ }^{19}$ that demonstrated that CCMD retention exerts indirect influence on the wear of the prostheses and direct influence on the intermaxillary relationships. The wear of the denture, according to the author, is directly influenced by the following factors: retention and stability, correct horizontal intermaxillary relationship (precision of the intermaxillary record with the mandible at the most retruded contact position), and correct vertical intermaxillary relationship (freeway space). The analysis of the technical quality and its association with the non-wear of the CCMD provided important data for the establishment of some guidelines for the improvement of the health service.

When the sociodemographic factors were analyzed separately (sociodemographic model), it was demonstrated that the marital status (not having a partner) favors the use of the CCMD. However, this variable was not significant in the final model, supporting the results obtained in previous studies. ${ }^{10,11,12,14,16}$ The Celebic et al. ${ }^{15}$ study showed that patients with a higher social self-perception were more dissatisfied with their CCD. However, the comparison between our results and previous studies is difficult due to the lack of standardization of the methods used to assign social level, indicators of living conditions, and quantification of social interactions. The study by Diehl et al. ${ }^{14}$ found an inverse relationship between age and adaptability to CCD due to decreased ability of facial muscles to adapt in older people.

No significant association was found between non-use of CCMD and previous experience with CCD and time of edentulism, corroborating results of other studies. ${ }^{13,16}$ Although a previous investigation showed that patients who had an edentulous mandible for a short time and were using their first CCMD were less satisfied than those who had longer experience with mandibular prostheses. ${ }^{15}$

The results showed no significant association between non-wear of CCMD and reabsorption of the mandibular residual ridge, corroborating findings of other studies. ${ }^{16,28}$ However, Fenlon et al. ${ }^{19}$ found a strong association between residual ridge conditions and the wearing of CCMD, but this association was indirect, since the anatomy of the mandibular residual ridge influenced the accuracy of the intermaxillary recordings and these, in turn, directly influenced CCD wearing. The difficulty of making a correct record of the intermaxillary relationships in highly reabsorbed or flat ridges would imply a greater incidence of errors at this stage. Other studies ${ }^{17,27}$ found a significant indirect association between residual border shape and satisfaction with PTC, masticatory ability and quality of life. ${ }^{27}$ Differences in the statistical methods used between the different studies, as well as particular characteristics of each sample, may explain the contradictory results found.

The results of the multivariate analysis confirmed the association of intermaxillary relationships with the non-wear of CCMD, since the stability of the CCMD, freeway space, and speech satisfaction favored the use of CCMD. The stability of the CCMD is associated with the correct horizontal (anteroposterior) relationship of the arches, while freeway space and satisfaction with speech are associated to the correct vertical relationship of the arches. The presence of irregular borders, also retained in the final model, led to a 3.1-fold increased risk of nonwearing the CCMD.

The prognostic ability of the multivariate models showed that the final model was the one with the highest specificity $(92.65 \%)$, with a greater power to discriminate who will wear the CCMD. However, the satisfaction model presented greater sensitivity $(81.05 \%)$, i.e., a greater power to discriminate who will not wear the CCMD. Thus, the area under the ROC curve shows that the predictive power of the "satisfaction" (0.8759) and "final" (0.8639) models for the non-wear of the CCMD are similar.

The high prevalence of people that did not wear the CCMD provided by Primary Health Care in the 
Public Health System is a special concern. The strategy of increasing the access of edentulous individuals to rehabilitation treatments must be accompanied by the resolution of this issue. The identification of factors associated with the non-wear of CCMD will optimize the Health Service.

The results of this study showed that the technical quality of dentures needs to be improved in order to minimize the recognized limitations of CCMD. This improvement involves the correct finishing and polishing of the prostheses to obtain the correct restoration of the intermaxillary relationship, especially in highly resorbed mandibles. This challenge has been shown to be related to the lack of retention of the mandibular border. ${ }^{17,27}$ The implant overdenture is an excellent alternative to the lack of CCMD retention, but it is not yet an easily accessible treatment for the general population. Martins et al..$^{29}$ pointed out that $6.2 \%$ of specialty reference centers of the cities evaluated in the National Program for Improving Access and Quality of Primary Care (PMAQ-AB, 2012) have a dental implant service. In addition, patient waiting time for treatment in the secondary care after being requested by a primary care professional

\section{References}

1. Douglass CW, Shih A, Ostry L. Will there be a need for complete dentures in the United States in 2020? J Prosthet Dent. 2002 Jan;87(1):5-8. https://doi.org/10.1067/mpr.2002.121203

2. Omran AR. The epidemiologic transition: a theory of the epidemiology of population change. 1971. Milbank Q. 2005;83(4):731-57. https://doi.org/10.1111/j.1468-0009.2005.00398.x

3. Nuttall N, Steele JG, Numm J. A guide to the UK Adult Dental Health Survey 1998. Br Dent J. 2001;Spec No:1-56.

4. Musacchio E, Perissinotto E, Binotto P, Sartori L, Silva-

Netto F, Zambon $S$ et al. Tooth loss in the elderly and its association with nutritional status, socio-economic and lifestyle factors. Acta Odontol Scand. 2007 Apr;65(2):78-86. https://doi.org/10.1080/00016350601058069

5. Joshipura KJ, Willett WC, Douglass CW. The impact of edentulousness on food and nutrient intake. J Am Dent Assoc. 1996 Apr;127(4):459-67. https://doi.org/10.14219/jada.archive.1996.0237

6. Burns DR, Unger JW, Elswick RK Jr, Beck DA. Prospective clinical evaluation of mandibular implant overdentures: part I: Retention, stability, and tissue response. J Prosthet Dent. 1995 Apr;73(4):35463. https://doi.org/10.1016/S0022-3913(05)80331-2 ranges from 60 to more than 90 days for this specialty. ${ }^{29}$ Therefore, it is necessary to better integrate primary and secondary care, essentially focusing on sharing clinical priorities. Therefore, our results point to the need of improving the quality of prostheses as a whole, not only regarding retention; moreover, it also alerts for an improvement in the flow of priority services for implant surgeries in order to decrease public financial costs.

\section{Conclusion}

The non-wear of complete conventional mandibular dentures (CCMD) was strongly associated with the technical quality of the prostheses and user satisfaction, while no association with sociodemographic and biological variables was observed.

\section{Acknowledgements}

The present study was supported by grants from the National Council for Scientific and Technological Development-CNPQ / Brazil, and the Minas Gerais State Research Support Foundation-FAPEMIG / Brazil.
7. Fitzpatrick B. Standard of care for the edentulous mandible: a systematic review. J Prosthet Dent. 2006 Jan;95(1):71-8. https://doi.org/10.1016/i.prosdent.2005.11.007

8. Raghoebar GM, Meijer HJ, van 't Hof M, Stegenga B, Vissink A. A randomized prospective clinical trial on the effectiveness of three treatment modalities for patients with lower denture problems: a 10 year follow-up study on patient satisfaction. Int J Oral Maxillofac Surg. 2003 Oct;32(5):498-503. https://doi.org/10.1016/S0901-5027(03)90434-0

9. Turkyilmaz I, Company AM, McGlumphy EA. Should edentulous patients be constrained to removable complete dentures? The use of dental implants to improve the quality of life for edentulous patients. Gerodontology. 2010 Mar;27(1):310. https://doi.org/10.1111/j.1741-2358.2009.00294.x

10. Carlsson GE, Otterland A, Wennström A, Odont D. Patient factors in appreciation of complete dentures. J Prosthet Dent. 1967 Apr;17(4):322-8. https://doi.org/10.1016/0022-3913(67)90002-9

11. Berg E. The influence of some anamnestic, demographic, and clinical variables on patient acceptance of new complete dentures. Acta Odontol Scand. 1984 Apr;42(2):119-27. https://doi.org/10.1080/00016357.1984.11978554 
12. Berg E, Johnsen TB, Ingebretsen R. Social variables and patient acceptance of complete dentures: a study of patients attending a dental school. Acta Odontol Scand. 1985 Aug;43(4):199-203. https://doi.org/10.3109/00016358509046499

13. Weinstein M, Schuchman J, Lieberman J, Rosen P. Age and denture experience as determinants in patient denture satisfaction. J Prosthet Dent. 1988 Mar;59(3):327-9. https://doi.org/10.1016/0022-3913(88)90184-9

14. Diehl RL, Foerster U, Sposetti VJ, Dolan TA. Factors associated with successful denture therapy. J Prosthodont. 1996 Jun;5(2):8490. https://doi.org/10.1111/j.1532-849X.1996.tb00279.x

15. Celebić A, Knezović-Zlatarić D, Papić M, Carek V, Baucić I, Stipetić J. Factors related to patient satisfaction with complete denture therapy. J Gerontol A Biol Sci Med Sci. 2003 Oct;58(10):M948-53. https://doi.org/10.1093/gerona/58.10.M948

16. Waas MA. The influence of clinical variables on patients' satisfaction with complete dentures.

J Prosthet Dent. 1990 Mar;63(3):307-10. https://doi.org/10.1016/0022-3913(90)90202-N

17. Fenlon MR, Sherriff M. An investigation of factors influencing patients' satisfaction with new complete dentures using structural equation modelling. J Dent. 2008 Jun;36(6):427-34. https://doi.org/10.1016/i.jdent.2008.02.016

18. Critchlow SB, Ellis JS. Prognostic indicators for conventional complete denture therapy: a review of the literature. J Dent. 2010 Jan;38(1):2-9. https://doi.org/10.1016/i.jdent.2009.08.004

19. Fenlon MR, Sherriff M, Walter JD. An investigation of factors influencing patients' use of new complete dentures using structural equation modelling techniques. Community Dent Oral Epidemiol. 2000 Apr;28(2):133-40. https://doi.org/10.1034/j.1600-0528.2000.028002133.x

20. Feine JS, Carlsson GE, Awad MA, Chehade A, Duncan WJ, Gizani S et al. The MacGill consensus statement on overdentures. Montreal, Quebec, Canada. May 24-25, 2002. Int J Prosthodont. 2002 Jul-Aug;15(4):413-4. https://doi.org/10.1111/j.1741-2358.2002.00003.x
21. Thomason JM, Feine J, Exley C, Moynihan P, Müller F, Naert I et al. Mandibular two implant-supported overdentures as the first choice standard of care for edentulous patients: the York Consensus Statement. Br Dent J. 2009 Aug;207(4):185-6. https://doi.org/10.1038/sj.bdj.2009.728

22. Instituto Brasileiro de Geografia e Estatística-IBGE. Censo 2010. Rio de Janeiro: Instituto Brasileiro de Geografia e Estatística; 2010.

23. Ministério da Saúde (BR). SB Brasil - Pesquisa Nacional de Saúde Bucal - 2010: resultados principais. Brasília, DF: Ministério da Saúde; 2011.

24. Sato Y, Hamada S, Akagawa Y, Tsuga K. A method for quantifying overall satisfaction of complete denture patients. J Oral Rehabil. 2000 Nov;27(11):952-7. https://doi.org/10.1046/i.1365-2842.2000.00579.x

25. Sato Y, Tsuga K, Akagawa Y, Tenma H. A method for quantifying complete denture quality. J Prosthet Dent. 1998 Jul;80(1):52-7. https://doi.org/10.1016/S0022-3913(98)70091-5

26. Cawood JI, Howell RA. A classification of the edentulous jaws. Int J Oral Maxillofac Surg. 1988 Aug;17(4):232-6. https://doi.org/10.1016/S0901-5027(88)80047-X

27. Yamaga $E$, Sato $Y$, Minakuchi S. A structural equation model relating oral condition, denture quality, chewing ability, satisfaction, and oral health-related quality of life in complete denture wearers. J Dent. 2013 Aug;41(8):710-7. https://doi.org/10.1016/i.jdent.2013.05.015

28. Berg E, Ingebretsen R, Johnsen TB. Some attitudes towards edentulousness, complete dentures, and cooperation with the dentist. A study of denture patients attending a dental school. Acta Odontol Scand. 1984 Dec;42(6):333-8. https://doi.org/10.3109/00016358409033612

29. Martins RC, Reis CM, Matta Machado AT, Amaral JH, Werneck MA, Abreu MH. Relationship between primary and secondary dental care in public health services in Brazil. PLoS One. 2016 Oct;11(10):e0164986. https://doi.org/10.1371/journal.pone.0164986 